\title{
Influence of ambient oxygenation and temperature on metabolic scope and scope for heart rate in the common sole Solea solea
}

\author{
Christel Lefrançois ${ }^{1,2, *}$, Guy Claireaux ${ }^{1}$ \\ ${ }^{1}$ Centre de Recherche sur les Ecosystèmes Marins et Aquacoles (CNRS-IFREMER), BP 5, L'Houmeau 17137, France \\ ${ }^{2}$ Present address: IMC — International Marine Centre, Localita Sa Mardini 09072 Torregrande-Oristano, Italy
}

\begin{abstract}
The objective of this study was to quantify the constraints exerted by temperature and oxygenation on both metabolic scope and scope for heart rate of the common sole Solea solea. We exposed sole to a large range of temperature and oxygenation conditions and a modelling procedure was implemented to describe metabolic and cardiac responses. Standard metabolic rate (SMR) rose exponentially from 4 to $24^{\circ} \mathrm{C}$, whereas active metabolic rate $(A M R)$ increased from 55.4 to $159.2 \mathrm{mg} \mathrm{O}_{2} \mathrm{~kg}^{-1} \mathrm{~h}^{-1}$ between 4 and $19.7^{\circ} \mathrm{C}$, and then dropped to $129.9 \mathrm{mg} \mathrm{O}_{2} \mathrm{~kg}^{-1} \mathrm{~h}^{-1}$ at $24^{\circ} \mathrm{C}$. In parallel, optimal temperature for maximising metabolic scope, defined as the difference between $A M R$ and $S M R$, was estimated to $18.8^{\circ} \mathrm{C}$. Active heart rates increased linearly with temperature and attained 15, 79 and 97 beats $\min ^{-1}$ at 4,20 and $24^{\circ} \mathrm{C}$, respectively. Hyperoxia had no influence on maximal heart rate nor on maximal metabolic rate. In hypoxic conditions, on the other hand, a significant decrease of the maximal metabolic rate was recorded when oxygen dropped below $75 \%$ air saturation. A significant decrease in maximal heart rate was also detected below $50 \%$ at 16 and $20^{\circ} \mathrm{C}$, and below $25 \%$ air saturation at $8^{\circ} \mathrm{C}$. The potential ecological consequences of the variation in sole metabolic and cardiac performances are discussed.
\end{abstract}

KEY WORDS: Metabolic scope $\cdot$ Heart rate $\cdot$ Biological performance $\cdot$ Temperature $\cdot$ Oxygen · Common sole

\section{INTRODUCTION}

Temperature and oxygen are environmental variables that profoundly influence fish activities, with consequences for their biological performance, e.g. growth, reproduction or survival (Priede 1985, Huey 1991). Through appropriate behavioural strategies, fish can take advantage of the thermal heterogeneity of their environment (Rudstam \& Magnuson 1985, Bryan et al. 1990, Huey 1991, Huntingford 1993). They are also able to alter their distribution pattern according to the amount of oxygen available in their surrounding milieu (Cech et al. 1990, Schurmann \& Steffensen 1992, Schurmann et al. 1998). Because of their morphology and negative buoyancy, flatfish have limited behavioural means to respond to environmental fluctuations. For instance, Petersen \& Pihl (1995) noted that during a hypoxic episode in the Kattegat (between Denmark and Sweden), dominant demersal roundfishes (cod Gadus morhua and whiting Merlangius merlangus) rapidly escaped, whereas dab and plaice were still found in areas with less than $20 \%$ air saturation. Parallel laboratory experiments showed that in $30 \%$ air saturated water, both flatfish species were already constrained and displayed negative mean growth (Petersen \& Pihl 1995). Because of this relatively restricted behavioural repertoire, flatfish are more liable to be exposed to environment-mediated changes in their biological performance (Duthie 1982, van den Thillart et al. 1994). The aim of the present study was to assess the influence of ambient temperature and oxygenation on the metabolism and cardiovascular physiology of a poorly studied but economically important flatfish species, the common sole Solea 
solea. To do so we determined in parallel the metabolic scope and scope for heart rate of sole exposed to combinations of oxygen and temperature conditions.

Metabolic scope (MS) is a suitable gauge for assessing the environmental influence on fish biological performance (Fry 1971). It is defined as the difference between active metabolic rate $(A M R)$ and standard metabolic rate $(S M R)$ measured in temperatureacclimated animals. SMR supports maintenance activities such as ventilation or osmoregulation. It corresponds to the oxygen consumption of a resting, fasted and non-maturing fish (Fry 1971). AMR is the maximum sustained aerobic metabolic rate measured in non-limiting conditions, i.e. those that do not interfere with oxygen supply (hypoxia, hypercapnia, ammonia or heavy metals, Fry 1971, Priede 1985, Neill et al. 1994). MS therefore represents the confines within which aerobic activities must be accommodated (Fry 1971, Evans 1990). According to Fry (1971), these activities must be viewed in a broad sense and include all physiological work such as swimming, feeding or growth. Any environmental condition causing a reduction of metabolic scope is thus liable to lead to energy budgeting conflicts between these activities (Priede 1985, Evans 1990). Temperature and oxygen are, respectively, potent controlling and limiting factors of fish metabolism, and they interact through their joint effects on MS (Fry 1971, Neill \& Bryan 1991, Claireaux \& Lagardère 1999). Using data from Chabot \& Dutil (1999), Claireaux et al. (2000) examined the consequences of reduced $M S$ in Atlantic cod Gadus morhua exposed to hypoxia. These authors showed that a linear relationship could be established between the $M S$ of cod and its growth. They also underlined the fact that the poor swimming ability of cod at low temperature (He 1991) could also be explained on the basis of reduced MS. More recently, Mallekh \& Lagardère (2002) reported a linear relationship between a temperature-mediated decrease in $M S$, the food intake and the growth of the turbot Scophthalmus maximus. In Solea solea, van den Thillart et al. (1998) showed that progressive hypoxia (from 80 to $20 \%$ air saturation) was accompanied by a large reduction of $M S$ and spontaneous swimming activity.

In fish, biological performances are intimately linked to the ability of the cardio-vascular system to provide tissues with the required amount of oxygen and nutrients. However, the level of work that the myocardium can sustain is strongly influenced by the physicochemical characteristics of the environment (Farrell et al. 1996, Farrell 1997, Lefrançois et al. 1998). In rainbow trout Oncorhynchus mykiss, a drop in temperature from 20 to $15^{\circ} \mathrm{C}$ results in a $\sim 25 \%$ reduction of the maximal heart rate (Farrell 1997). It has long been recognised that this decline accounts almost entirely for the temperature-induced decrease in cardiac output (Randall 1968). Oxygen depletion also results in reduced heart performances. For instance, the maximal heart rate of sea bass Dicentrarchus labrax exposed to progressive hypoxia is reduced from 65 to 40 beats $\mathrm{min}^{-1}$ between $\sim 90$ and $\sim 50 \%$ of air saturation (Lefrançois et al. 1998). The relationship between heart rate and metabolism is not straightforward in fish (Thorarensen et al. 1996). However, heart rate is liable to provide information about the environmental impact on fish physiological state, thereby widening our understanding of the general relationship between fish and their environment (Priede \& Young 1977, Priede \& Tytler 1977, Armstrong 1986, Lucas et al. 1991). Moreover, heart rate is one of the few correlates to metabolic demand that can be monitored in free-swimming fish using telemetry (Armstrong 1986, Bushnell \& Brill 1991, Lucas et al. 1991, Sureau \& Lagardère 1991, Claireaux et al. 1995). By examining the influence of ambient temperature and oxygenation on both $M S$ and scope for heart rate, we aimed to design an analytical tool for investigating the ecological relevance of the environmental constraints on sole.

\section{MATERIALS AND METHODS}

Fish. Sole were allocated into 2 groups. Group 1 consisted of 8 fish $(0.15 \mathrm{~kg} \pm 0.08 \mathrm{SE})$ and Group 2 of 6 fish $(0.82 \mathrm{~kg} \pm 0.09 \mathrm{SE})$. Both groups of fish were collected in the Gironde estuary (France). Upon arrival at the laboratory, fish were transferred into $500 \mathrm{l}$ indoor rearing tanks with a sand bottom, where the temperature followed natural seasonal changes. Tanks were supplied with recirculated and filtered natural seawater (water renewal rate: 30 to $50 \%$ per week). Fish were fed twice a week on frozen mussels or fresh oysters. Feeding was discontinued $24 \mathrm{~h}$ before fish were used in an experiment.

Oxygen consumption measurement. The complete experimental set-up (Fig. 1) was placed in a thermoregulated room. To measure fish oxygen consumption, 2 stop-flow respirometers were used (R). Their volume was adapted to the size of the sole, $6.8 \mathrm{l}$ for fish from Group 1 and 23.81 for fish from Group 2. The respirometers were placed in a larger tank $(\mathrm{T})$ where water oxygenation was regulated via a counter-current gas equilibration column (C) bubbled with (1) oxygen to create hyperoxia, (2) air to maintain normoxia or (3) nitrogen to establish hypoxic conditions. The respirometers were supplied with water from the outer tank at a flow rate of $101 \mathrm{~min}^{-1}$ via a pump (P). Oxygen concentration in the respirometers was monitored using oxygen probes (Orbisphere Laboratories 27141, Op) connected to a multichannel oxygen measuring system (Orbi- 


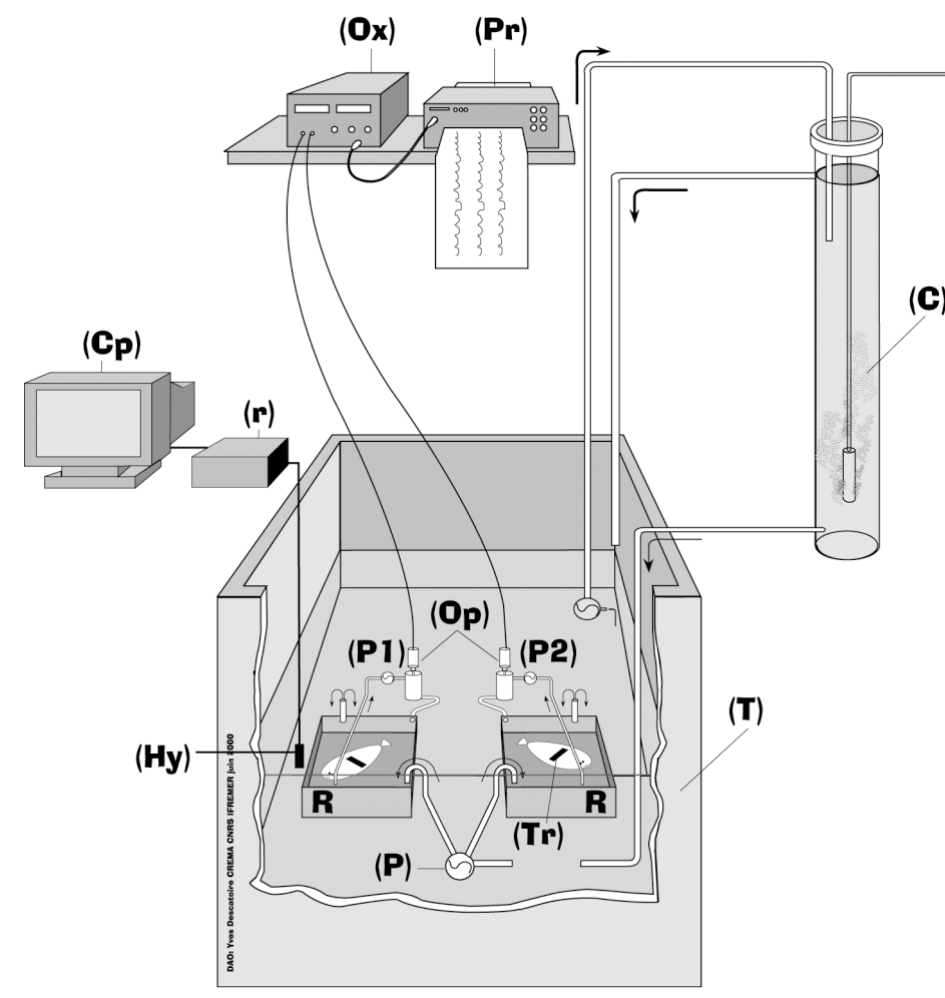

Fig. 1. Experimental set-up (for explanations see subsections 'Oxygen consumption measurement' and 'Heart rate measurement' in 'Materials and methods')

sphere Laboratories 2610, Ox) and a chart recorder (Pr). Oxygen probes were inserted in thermoregulated cuvettes connected to the respirometer via 2 pumps $\left(\mathrm{P}_{1}\right.$ and $\mathrm{P}_{2}$ ). These pumps ensured appropriate mixing in the measuring chambers. Oxygen probes were calibrated daily. To measure fish oxygen consumption, the pump (P) controlling the water supply to the respirometers was turned off and the decrease in the chambers' water oxygen content monitored during the next 15 min. Oxygen consumption $\left(\mathrm{MO}_{2}\right.$ in $\left.\mathrm{mgO}_{2} \mathrm{~kg}^{-1} \mathrm{~h}^{-1}\right)$ was calculated using the following formula:

$$
M O_{2}=\Delta C_{\mathrm{w}} O_{2} \times \Delta t^{-1} \times V O L_{\mathrm{resp}} \times M^{-1}
$$

where $\Delta C_{\mathrm{w}} \mathrm{O}_{2}$ is the change in water oxygen concentration $\left(\mathrm{mg} \mathrm{O}_{2} \mathrm{l}^{-1}\right)$ during $\Delta t$ the measuring time (h), $V O L_{\text {resp }}$ is the volume of the respirometer minus the volume of the fish (l), and $M$ the mass of the fish (kg).

Routine oxygen consumption was standardised to a body mass of $100 \mathrm{~g}$ using the following formula (Schurmann \& Steffensen 1997):

$$
M O_{2 \text { cor }}=M O_{2 \text { meas }} \times\left(M_{\text {meas }} \times M_{\text {cor }}{ }^{-1}\right)^{1-A}
$$

where $\mathrm{MO}_{2 \text { cor }}$ is the mass specific $\mathrm{MO}_{2}$ of a fish weighing $M_{\text {cor }}, M O_{2 \text { meas }}$ the mass specific $M O_{2}$ measured, and $M_{\text {meas }}$ the mass of the fish. $A$ is the allometric exponent describing the relationship between metabolic rate and body mass (0.8: van den Thillart et al. 1994). Background oxygen consumption by micro-organisms was routinely assessed before the fish was transferred into the chamber by recording the oxygen consumption of an empty respirometer. In some cases, only 1 of the 2 chambers contained a fish, the other being left c) empty to assess the changes in background $\mathrm{MO}_{2}$ over time. Oxygen consumption by micro-organisms never exceeded $10 \%$ of fish $\mathrm{MO}_{2}$, but was accounted for in the calculations.

Heart rate measurement. Heart rate (HR) was monitored in fish from Group 2 by recording the acoustic pulse rate of an electrocardiogram transmitter ( $\mathrm{Tr})$. The tag and the tagging procedure are described in Claireaux et al. (1995). Acoustic signals from the tag were detected by a hydrophone (Vemco VH65, Hy) placed in the outer tank and connected to a receiver (Vemco VR20, r). The receiver was interfaced with a computer $(\mathrm{Cp})$ that processed and stored the data. HR (beat $\mathrm{min}^{-1}$ ) were averaged over the $15 \mathrm{~min}$ period corresponding to the oxygen consumption measurement period.

Protocol for Group 1. All fish from Group 1 were tested at each of the 6 experimental temperatures $(4$, $8,12,16,20$ and $24^{\circ} \mathrm{C}$ ). Ten days before each experimental trial, Group 1 fish were transferred into a tank situated in the thermoregulated room where they were acclimated to the experimental temperature. The fish acclimation procedure was designed in such a way that experimental temperatures were always within $2^{\circ} \mathrm{C}$ of the temperature prevailing in the rearing tanks $\left(20\right.$ and $24^{\circ} \mathrm{C}$ in summer, 12 and $16^{\circ} \mathrm{C}$ in autumn, 4 and $8^{\circ} \mathrm{C}$ in winter). In the thermoregulated room the photoperiod matched the natural photoperiod cycle. Following acclimation, each fish was individually tested in hypoxia. The fish was first chased until exhaustion in order to raise its metabolic rate towards $A M R$. It was then rapidly transferred into the respirometer chamber and the monitoring of the water oxygen content immediately started. After measuring oxygen consumption under normoxic conditions, water oxygenation was progressively reduced in a stepwise manner (step: $20 \%$ air saturation) down to $20 \%$ air saturation. In order to improve the modelling of the relationship between $M O_{2 \max }$ and ambient oxygenation, fish were chased between hypoxic steps. Following exhaustion ( $~ 5 \mathrm{~min})$, the respirometer was washed with hypoxic water until the desired oxygen level was reached (about $1 \mathrm{~min}$ ). The respirometers were then closed and the water oxygenation level in the chambers monitored during the next $30 \mathrm{~min}$. Only the last half of the monitoring periods was used to calculate oxygen consumption. After the last measurement, normoxic conditions were restored. 
During the next $48 \mathrm{~h}$, measurements of oxygen consumption were carried out to estimate $S M R$. Oxygen consumption was automatically recorded on the undisturbed animals. The pump controlling the water supply to the respirometers was turned off for $15 \mathrm{~min}$ every hour using a timer. The $\mathrm{MO}_{2}$ values obtained were used to construct frequency distribution histograms. According to the method proposed by Steffensen et al. (1994), the peak of the distribution was considered as an estimator of the $S M R$. Since sole are more active during the night, only diurnal $\mathrm{MO}_{2}$ values were considered. To improve this estimation further, we only considered the diurnal values recorded during the last day of each experimental trial, i.e. the third day. We assumed that by this time, stress due to handling and hypoxia had disappeared. After each experiment, fish were anaesthetised $\left(0.3 \mathrm{ml} \mathrm{l}^{-1} 2\right.$-phenoxyethanol), weighed and placed back into the rearing tanks.

Protocol for Group 2. The experimental protocol followed for this group was identical to the previous one with 2 exceptions:

- Firstly, $48 \mathrm{~h}$ before being transferred into the respirometer, each fish was anaesthetised $\left(0.5 \mathrm{ml} \mathrm{l}^{-1}\right.$ 2-phenoxyethanol), weighed and equipped with a cardiac transmitter $(10 \mathrm{~cm}$ long, $1.6 \mathrm{~cm}$ in diameter, $37.5 \mathrm{~g}$ in air). Sole were placed on an operating table and gills were continuously perfused with oxygenated water containing anaesthetic $\left(0.3 \mathrm{ml} \mathrm{l}^{-1}\right.$ of 2 -phenoxyethanol). Two electrodes were inserted under the skin (pigmented face) near the pericardial cavity and connected to an accoustic tag, which was sutured externally and transversally to the principal axis of the body. Tagging procedure took less than $15 \mathrm{~min}$ and fish resumed ventilatory activity within $5 \mathrm{~min}$ of being ventilated with anaesthetic free water.

- Secondly, the step decrease in ambient oxygenation started from hyperoxia (175 to $200 \%$ ) instead of normoxia. Preliminary studies had shown that estimation of the maximal heart rate was considerably more accurate when the oxygenation range was extended to hyperoxia. Hyperoxic conditions were set 15 to $20 \mathrm{~min}$ prior to the start of the experiment by bubbling pure oxygen in the gas equilibration column. Each Group 2 fish was successively exposed to this experimental protocol, which was repeated after acclimation at 8 (January), 16 (March) and $20^{\circ} \mathrm{C}$ (April to May). Values of $\mathrm{MO}_{2}$ measured from resting tagged fish were not included in the modelling procedure of the $S M R$, as the tag is likely to cause increased energy expenditure notably due to additional drag (Lewis \& Muntz 1984, Mellas \& Haynes 1985, Lefrançois et al. 2001).

Statistical analysis. Prior to analysis, data were $\log _{10^{-}}$ transformed to ensure the normality of the data set and to improve homogeneity of variances (Sokal \& Rohlf 1981). At each experimental temperature, the effect of ambient oxygenation on $M O_{2 \max }$ and $H R_{\max }$ was analysed using a randomised-block ANOVA (Von Ende 1993). In order to analyse the effect of supersaturation, only $\mathrm{MO}_{2}$ recorded from Group 2 fish (at 8, 16 and $20^{\circ} \mathrm{C}$ ) were considered. Each fish was considered as a different block within which the oxygen treatment was applied. $M O_{2 \max }$ and $H R_{\max }$ values were pooled among 7 oxygen saturation classes (from 0 to $175 \%$ ) using a class interval of 25. The null hypothesis was rejected at $\mathrm{p}<0.05$. When necessary, an a posteriori Student-Newman-Keuls (SNK) test was applied ( $\mathrm{p}<$ 0.05). Throughout the text, data are routinely expressed as mean $\pm \mathrm{SE}$ (standard error).

Concept. The modelling of the $M S$ as a function of water oxygenation is based on the fact that, for any given routine oxygen consumption $\left(\mathrm{MO}_{2}\right)$, we considered a limiting oxygen concentration ( $L O C)$, below which that particular oxygen demand cannot be satisfied (Beamish 1964, Fry 1971, Gehrke 1988, Neill \& Bryan 1991, Claireaux \& Lagardère 1999). It implies that during progressive hypoxia, routine $\mathrm{MO}_{2}$ is oxygen independent until the corresponding LOC is reached. Below that point, $\mathrm{MO}_{2}$ becomes oxygen dependent and declines with water oxygen content. The relationships between ambient oxygenation and maximum sustainable oxygen consumption $\left(\mathrm{MO}_{2 \max }\right)$ was described in sea bass Dicentrarchus labrax using an asymptotic curve, known as the $\mathrm{LOC}_{\mathrm{MO}_{2}}$ curve (Claireaux \& Lagardère 1999). According to these authors, the asymptote was attained at $100 \%$ air saturation and represented the maximal metabolic rate that bass could sustain in normoxic conditions, i.e. $A M R$. In the present study, we also considered this asymptote as an estimator of $A M R$. As a consequence, we hypothesized that sole $M S$ (i.e. $A M R$ minus $S M R$ ) was maximal under normoxic conditions. When the ambient oxygenation level decreases, $M S$ gradually shrinks as the maximal sustainable $\mathrm{MO}_{2}$ departs from $A M R$ and drops along the $L O C_{M_{2}}$ curve. At the critical oxygen saturation, i.e. when the maximal sustainable $M O_{2}$ is equal to $S M R$, the $M S$ is nil.

We extended the concept of the LOC curve to $H R$. For any given $H R$, we considered a limiting oxygen concentration $(L O C)$, below which $H R$ switches from being oxygen-independent to being oxygen-dependent. The description of the restriction imposed by ambient oxygenation on $H R_{\max }$ was carried out using the same type of curve as described for $M O_{2 \max }$, i.e. the $L O C_{\mathrm{HR}}$ curve.

Metabolic scope. Mathematical equations: This was estimated as the difference between the maximal metabolic rate and the SMR (Eq. 1 in Table 1).

Maximal and active metabolic rate: In the present experimental conditions, the maximal metabolic rate was related to the ambient temperature and oxygen- 
Table 1. Definition and formulae of variables and parameters used in the metabolic scope model where $T$ is temperature $\left({ }^{\circ} \mathrm{C}\right)$ and $\mathrm{C}_{W} \mathrm{O}_{2}$ is air saturation (\%)

\begin{tabular}{|c|c|c|c|c|}
\hline Variable & Definition & Units & Equation & Equation no. \\
\hline$M S$ & Metabolic scope & $\mathrm{mgO}_{2} \mathrm{~kg}^{-1} \mathrm{~h}^{-1}$ & $M O_{2 \max }-S M R$ & (1) \\
\hline$M O_{2 \max }$ & Maximal metabolic rate & $\mathrm{mgO}_{2} \mathrm{~kg}^{-1} \mathrm{~h}^{-1}$ & $A M R \times\left[1-\exp \left(\alpha_{1} \times C_{W} O_{2}^{\beta 1}\right)\right]$ & $(2)$ \\
\hline$A M R$ & Active metabolic rate & $\mathrm{mgO}_{2} \mathrm{~kg}^{-1} \mathrm{~h}^{-1}$ & $\delta \times\left(\frac{T_{\mathrm{m}}-T}{T_{\mathrm{m}}-T_{\mathrm{opt}}}\right)^{\omega} \times \exp \left[-\omega \times\left(\frac{T_{\mathrm{m}}-T}{T_{\mathrm{m}}-T_{\mathrm{opt}}}\right)\right]$ & (3) \\
\hline$S M R$ & Standard metabolic rate & $\mathrm{mgO}_{2} \mathrm{~kg}^{-1} \mathrm{~h}^{-1}$ & $a \times \exp (b \times T)$ & $(4)$ \\
\hline Parameter & Definition & Mean \pm SE & No. of observations & \\
\hline$a$ & Constant & $15.450 \pm 1.833$ & 6 & \\
\hline$b$ & Constant & $0.052 \pm 0.006$ & 6 & \\
\hline$\alpha_{1}$ & Constant & $-0.005 \pm 0.001$ & 484 & \\
\hline$\beta_{1}$ & Constant & $1.320 \pm 0.076$ & 484 & \\
\hline$\delta$ & Constant & $1038.410 \pm 154.724$ & 484 & \\
\hline$\omega$ & Constant & $1.870 \pm 1.509$ & 484 & \\
\hline$T_{\mathrm{m}}$ & Maximal temperature & $30.480 \pm 4.837$ & 484 & \\
\hline$T_{\mathrm{opt}}$ & Optimal temperature & $19.740 \pm 0.405$ & 484 & \\
\hline
\end{tabular}

ation. This relationship was described using Eq. (2) (Table 1), where $\alpha_{1}$ and $\beta_{1}$ are constants. At a given temperature, this equation defines the $\mathrm{LOC}_{\mathrm{MO}_{2}}$ curve, illustrating the relationship between the maximal metabolic rate and the ambient oxygenation. In Eq. (2), the asymptote corresponds to the $A M R$, the value of which is temperature dependent (Eq. 3). Eq. (3) was proposed by Strasbaka \& Gnauck (1985) to describe biological temperature-dependent processes showing a thermal optimum. In this equation, $T$ is the experimental temperature, $T_{\text {opt }}$ is the optimal temperature, i.e. at $T_{\text {opt }}$ $A M R$ is maximised, and $T_{\mathrm{m}}$ is the maximal temperature for $A M R$, i.e. at $T_{\mathrm{m}}, A M R=0 . \delta$ and $\omega$ are constants.

Standard metabolic rate: $S M R$ was described as a function of temperature using an exponential relationships (Eq. 4 in Table 1), where $a$ and $b$ are 2 constants.
Active heart rate: The relationships between temperature, oxygen and $\left(H R_{\max }\right)$ were described using Eq. (5) (Table 2), where $\alpha_{2}$ and $\beta_{2}$ are 2 constants and $A H R$ the active heart rate. The relationship between the latter and the temperature was established using a linear equation (Eq. 6 in Table 2), where $c$ is the slope and $d$ the intercept.

\section{RESULTS}

\section{Standard metabolic rate}

The method used to determine $S M R$ is illustrated in Fig. 2A and the results obtained at each of the 6 experimental temperatures are presented in Fig. 2B. These data were used to fit Eq. (4) (Table 1).

Table 2. Definition and formulae of variables and parameters used in the model of the scope for increasing heart rate (HR) where $T$ is temperature $\left({ }^{\circ} \mathrm{C}\right.$ ) and $\mathrm{C}_{W} \mathrm{O}_{2}$ is air saturation (\%)

\begin{tabular}{|c|c|c|c|c|}
\hline Variable & Definition & Units & Equation & Equation no. \\
\hline$H R_{\max }$ & Maximal heart rate & beat $\min ^{-1}$ & $A H R \times\left[1-\exp \left(\alpha_{2} \times C_{W} O_{2}^{\beta_{2}}\right)\right]$ & $(5)$ \\
\hline$A H R$ & Active heart rate & beat $\min ^{-1}$ & $c \times T+d$ & (6) \\
\hline Parameter & Definition & Mean \pm SE & No. of observations & \\
\hline$\alpha_{2}$ & Constant & $-0.077 \pm 0.028$ & 178 & \\
\hline$\beta_{2}$ & Constant & $0.83 \pm 0.11$ & 178 & \\
\hline C & Slope & $4.10 \pm 0.13$ & 178 & \\
\hline$d$ & Intercept & $-1.71 \pm 0.35$ & 178 & \\
\hline
\end{tabular}



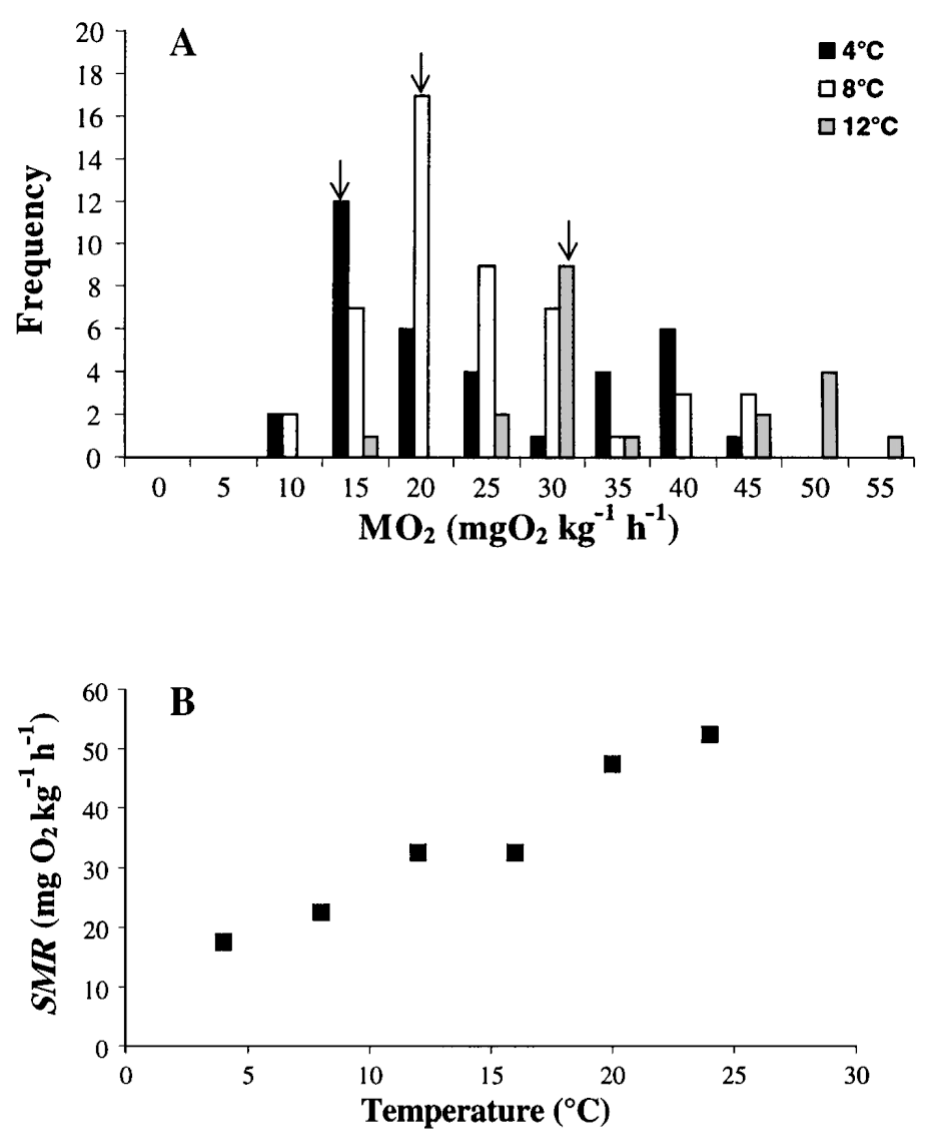

Fig. 2. Solea solea. (A) Examples of frequency distribution of oxygen consumption $\left(\mathrm{MO}_{2} \mathrm{mg} \mathrm{O}_{2} \mathrm{~kg}^{-1} \mathrm{~h}^{-1}\right)$ at 4,8 and $12^{\circ} \mathrm{C}$ during resting conditions. Arrows indicate peak of distribution at each of these 3 temperatures, which is considered the estimation of standard metabolic rate (SMR). (B) Estimation of $S M R$ at the 6 experimental temperatures. Only $\mathrm{MO}_{2}$ measurements carried out on Group 1 individuals were considered

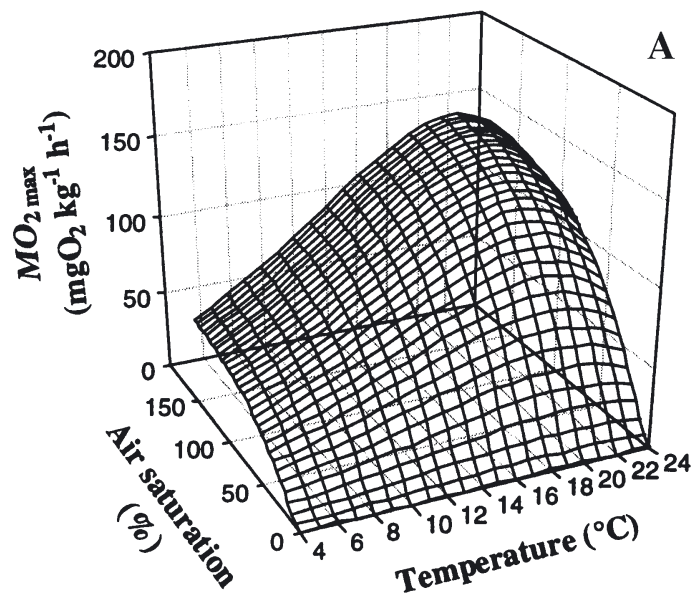

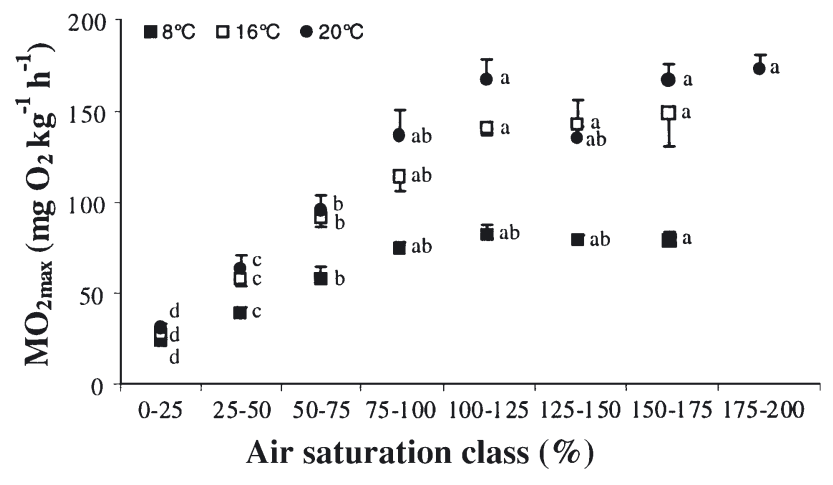

Fig. 3. Solea solea. Oxygen effect on maximal oxygen consumption $\left(\mathrm{MO}_{2}\right)$ at 8,16 and $20^{\circ} \mathrm{C}$. Values are mean $\mathrm{MO}_{2 \max } \pm \mathrm{SE}$ in $\mathrm{mgO}_{2} \mathrm{~kg}^{-1} \mathrm{~h}^{-1}$. At 1 experimental temperature, means not sharing a common superscript are significantly different $(p<0.05$, ANOVA)

\section{$A M R$ and maximal metabolic rate}

At each experimental temperature, maximal oxygen consumption differed significantly among individuals (ANOVA; $\mathrm{p}<0.01$ ). A significant effect of the oxygen level on $M O_{2 \max }$ was also found (ANOVA; $\mathrm{p}<0.001$ ). A posteriori multiple range tests (SNK) showed that as long as water saturation remained above $75 \%$, oxygenation had no significant influence on $M O_{2 \max }$ (Fig. 3). Below this limit, $M O_{2 \max }$ in each class of air saturation were significantly different.

The general model describing the combined effect of ambient oxygenation and temperature on $M O_{2 \max }$ was fitted using the whole data set (Eqs. 2 \& 3 in Table 1 and Fig. 4A). When compared with the experimental data, the maximal oxygen consumption predicted by this model showed a slight overestimation at $4^{\circ} \mathrm{C}$ (Fig. 5A)

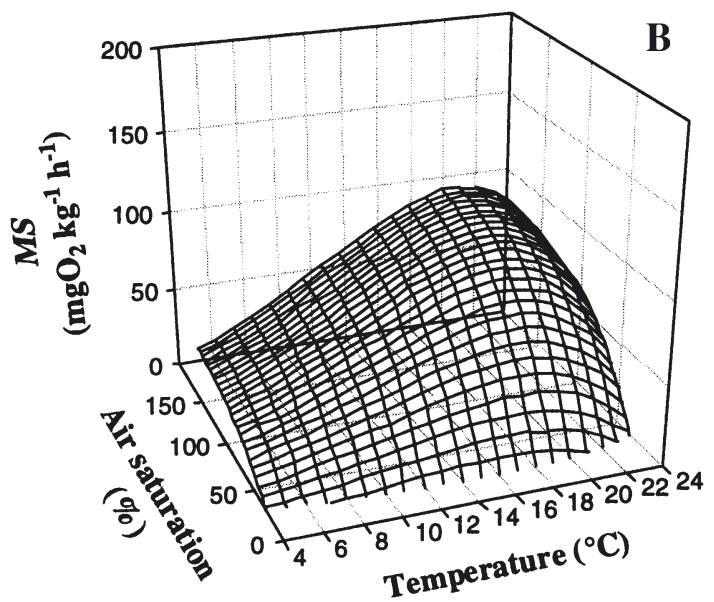

Fig. 4. Solea solea. Effect of oxygen and temperature on (A) maximal oxygen consumption $\left(M_{2 \max }\right)$ and (B) metabolic scope (MS) 
and a slight underestimation at $12^{\circ} \mathrm{C}$ (Fig. 5C). However, an overall good fit between the observed and predicted values of $M O_{2 \max }$ was found (Fig. $5 \mathrm{G}, \mathrm{r}^{2}=0.79, \mathrm{n}=484$ ). Furthermore, the slope and intercept of the relationship between observed and predicted values were not significantly different from 1 and 0 respectively $(p>0.05)$.
$A M R$ attained under normoxia quickly increased from 55.4 at $4^{\circ} \mathrm{C}$ to a maximum of $159.2 \mathrm{mg} \mathrm{O}_{2}$ $\mathrm{kg}^{-1} \mathrm{~h}^{-1}$ at the optimal temperature, i.e. $19.7^{\circ} \mathrm{C}$ (Eq. 3 in Table 1, Fig. 6). Above $19.7^{\circ} \mathrm{C}$, however, a downward trend was observed and, at $24^{\circ} \mathrm{C}, A M R$ was $129.9 \mathrm{mg} \mathrm{O}_{2} \mathrm{~kg}^{-1} \mathrm{~h}^{-1}$.
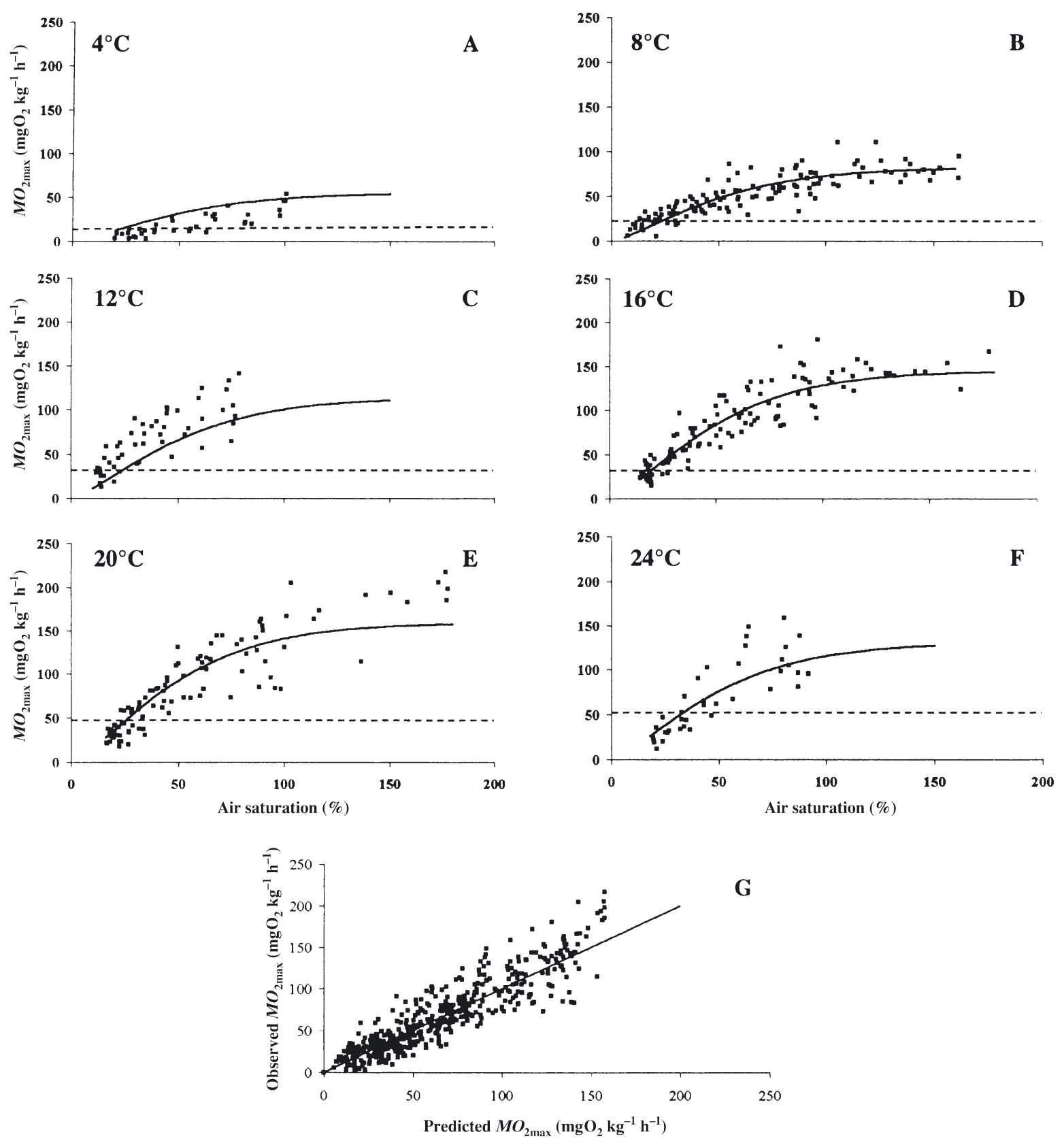

Fig. 5. (A-F). Solea solea. Effect of water temperature (A: 4, B: 8, C: 12, D: 16, E: 20 and F: $24^{\circ} \mathrm{C}$ ) and oxygenation on maximal oxygen consumption $\left(\mathrm{MO}_{2 \mathrm{max}}\right)$. Solid lines indicate $\mathrm{LOC}_{\mathrm{MO}_{2}}$ curves (Eqs. 2 \& 3, Table 1) fitted to $\mathrm{MO}_{2 \max }$ recorded at the different level of oxygenation (closed squares). Dotted lines represent standard metabolic rate (SMR). All oxygen consumptions are corrected for a sole weighing $100 \mathrm{~g}$. (G) Predicted and observed maximal oxygen consumption (solid line represents observations = predictions). Model testing: linear regression analysis; intercept $-1.03 \pm 1.82$, p $>0.5$; slope $1.03 \pm 0.02, p<0.0001, n=484$, $\mathrm{r}^{2}=0.79 ;$ ANOVA, $F=1895.6, \mathrm{p}<0.0001$ 


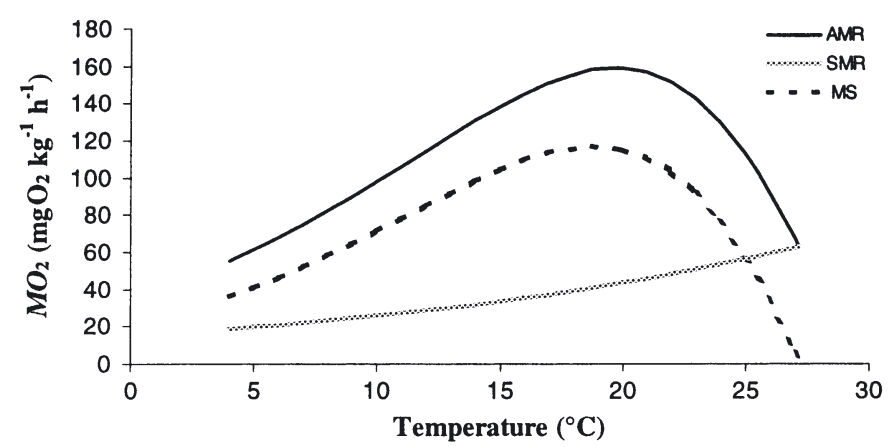

Fig. 6. Solea solea. Influence of ambient temperature on active metabolic rate $(A M R$, Eq. 3, Table 1), standard metabolic rate $(S M R$, Eq. 4, Table 1) and metabolic scope (MS, Eq. 1 with $\mathrm{C}_{W} \mathrm{O}_{2}=100 \%$, Table 1)

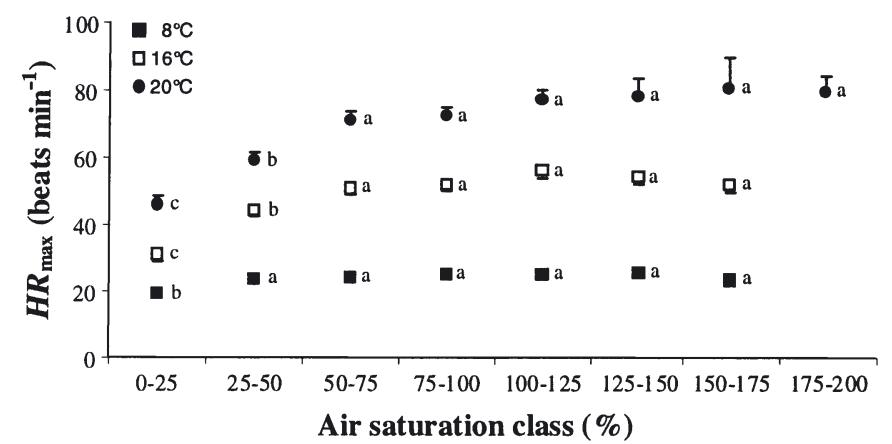

Fig. 7. Solea solea. Oxygen effect on maximal heart rate $\left(H R_{\max }\right)$ sustainable at 8,16 and $20^{\circ} \mathrm{C}$. Values are mean $H R_{\max }$ $\pm \mathrm{SE}$ in beats $\mathrm{min}^{-1}$. At each temperature, means not sharing a common superscript are significantly different $(\mathrm{p}<0.05$, ANOVA)

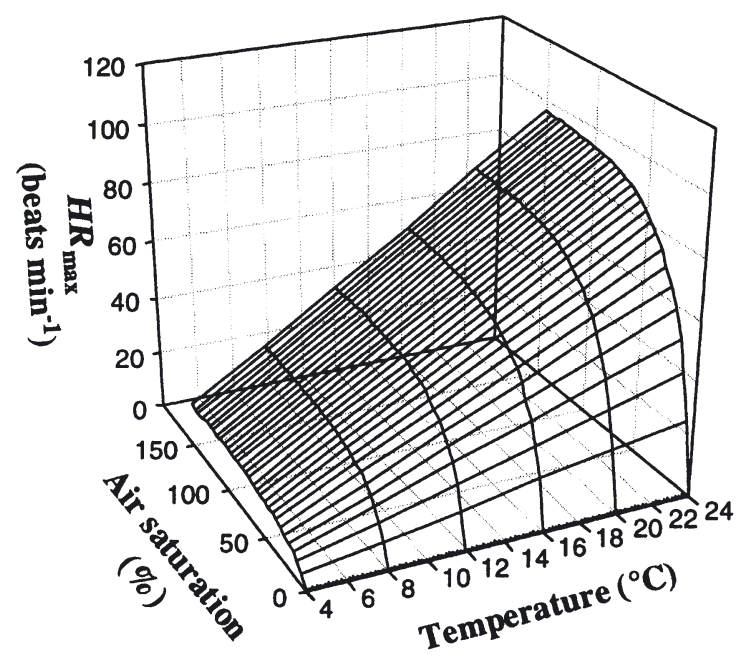

Fig. 8. Solea solea. Effect of oxygen and temperature on maximal heart rate $\left(H R_{\max }\right.$ Eqs. $5 \& 6$, Table 2$)$

\section{Metabolic scope}

The influence of water temperature and oxygenation on $M S$ was modelled by subtracting Eq. (4) from Eq. (2) (Table 1 and Fig. 4B). Due to the exponential increase of $S M R$ with temperature, $M S$ was found to be maximal at $18.8^{\circ} \mathrm{C}$ and to be zero at $27.2^{\circ} \mathrm{C}$ (Fig. 6).

\section{Heart rate}

At each experimental temperature, significant interindividual differences in $H R_{\max }$ were found (ANOVA, $\mathrm{p}<0.001)$. The effect of the ambient oxygenation on $H R_{\max }$ was also significant (ANOVA, $\mathrm{p}<0.001$ ). Multiple range tests (SNK) showed that down to $50 \%$ air saturation, ambient oxygenation had no significant effect on $H R_{\max }$ (Fig. 7). Below that threshold, however, $H R_{\max }$ was significantly different in each air saturation class at 16 and $20^{\circ} \mathrm{C}$. At $8^{\circ} \mathrm{C}$, however, a significant decrease of $H R_{\max }$ was recorded only for the 0 to $25 \%$ air saturation class.

The model describing the combined effect of oxygenation and temperature on $H R_{\max }$ was established according to Eq. (5) (Table 2, Fig. 8). An overall good fit between the observed and the predicted $H R_{\max }$ ( $L O C_{H R}$ curves) was observed at $20^{\circ} \mathrm{C}$ (Fig. $9 \mathrm{C}$ ). At $8^{\circ} \mathrm{C}$, the $L O C_{H R}$ curve showed a slight overestimation of $H R_{\max }$ above $50 \%$ air saturation and a slight underestimation at the lower levels (Fig. 9A). At $16^{\circ} \mathrm{C}$, an overestimation of $H R_{\max }$ can be observed (Fig. 9B). Globally, however, observed and predicted $H R_{\max }$ exhibited a linear relationship (Fig. $8 \mathrm{D}, \mathrm{n}=178, \mathrm{r}^{2}=0.91$ ) and the slope and intercept were not significantly different from 1 and 0 respectively ( $p>0.05)$.

\section{DISCUSSION}

\section{Effect of the temperature}

The thermal dependence of sole metabolism is illustrated by the exponential increase of $S M R$ (Fig. 6) between $4^{\circ} \mathrm{C}\left(17.5 \mathrm{mg} \mathrm{O}_{2} \mathrm{~kg}^{-1} \mathrm{~h}^{-1}\right)$ and $24^{\circ} \mathrm{C}\left(52.5 \mathrm{mg} \mathrm{O}_{2}\right.$ $\mathrm{kg}^{-1} \mathrm{~h}^{-1}$ ). Our values for $S M R$ in sole are generally lower than the average values reported for flatfish e.g. 26.6 and $139.8 \mathrm{mg} \mathrm{O}_{2} \mathrm{~kg}^{-1} \mathrm{~h}^{-1}$ at 4 and $24^{\circ} \mathrm{C}$ respectively (Duthie 1982). This discrepancy is particularly significant at high temperatures. It is worth noticing that Duthie (1982) established a general relationship between temperature and $S M R$ based on a data-set collected on 14 flatfish species, among which 4 are from the genus Platichthys, 7 from the genus Pleuronectes and none from the genus Solea. Therefore, the relationship established by Duthie may not be 

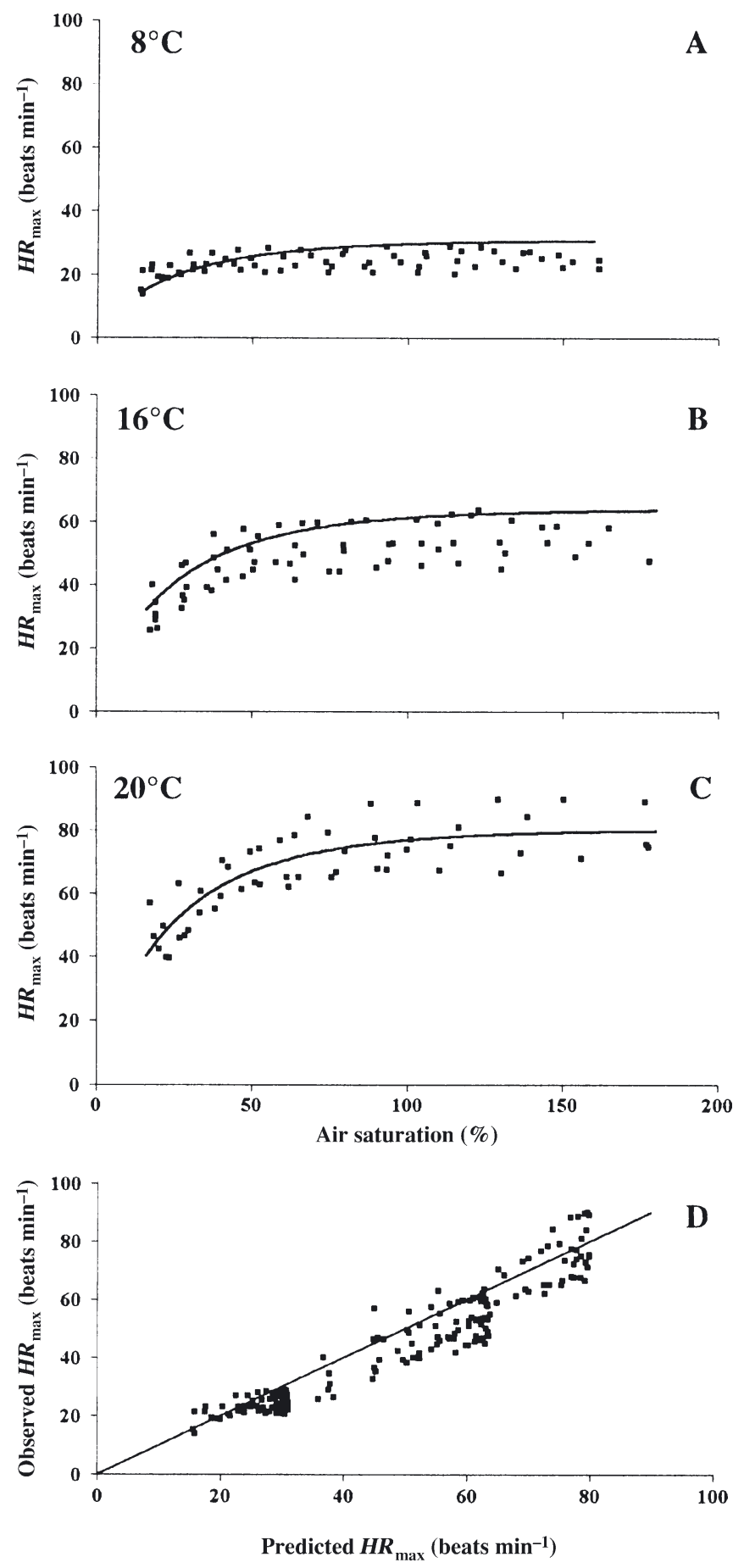

Fig. 9. Solea solea. (A-C) Effect of water temperature (A: 8, B: 16 and $\mathrm{C}: 20^{\circ} \mathrm{C}$ ) and oxygenation on maximal heart rate $\left(H R_{\max }\right)$. Solid lines indicate $L O C_{H R}$ curves fitted to $H R_{\max }$ recorded at the different level of oxygenation (closed squares). $L O C_{H R}$ curves were calculated using Eqs. (5) \& (6) with the adequate experimental temperature ( $T$ ). (D) Predicted and observed maximal heart rate (solid line represents observations $=$ predictions). Model testing: linear regression analysis; intercept $-3.18 \pm 1.62, \mathrm{p}>0.05$; slope $0.97 \pm 0.02$, $\mathrm{p}<0.0001, \mathrm{n}=178, \mathrm{r}^{2}=0.91 ;$ ANOVA, $F=1685.0, \mathrm{p}<0.0001$ fully representative of the common sole. On the other hand, our results are in accordance with those of van den Thillart et al. (1994), who estimated $S M R$ of a $100 \mathrm{~g}$ common sole to be $41 \mathrm{mg} \mathrm{O}_{2} \mathrm{~kg}^{-1} \mathrm{~h}^{-1}$ at $20^{\circ} \mathrm{C}$.

The influence of thermal conditions on sole metabolism is also illustrated by the bell-shaped curve describing the changes in $A M R$ with temperature (Fig. 6). The maximal value attained at the optimal temperature (159.2 $\mathrm{mg} \mathrm{O}_{2} \mathrm{~kg}^{-1} \mathrm{~h}^{-1}$ at $19.7^{\circ} \mathrm{C}$ ) is in accordance with that measured by van den Thillart et al. (1994) in $20^{\circ} \mathrm{C}$ acclimated sole $\left(152.2 \mathrm{mg} \mathrm{O}_{2} \mathrm{~kg}^{-1} \mathrm{~h}^{-1}\right.$ ). The scarcity of published data on active metabolism in flatfish prevents thorough inter-specific comparison. Most of the available data indeed relate to resting or routine metabolism and only cover a narrow range of the species' thermal range. To our knowledge, only Mallekh \& Lagardère (2002) have examined the influence of a large range of acclimation temperature on $A M R$ in a flatfish, the turbot Scophthalmus maximus. According to their study, $A M R$ was $107 \mathrm{mgO}_{2} \mathrm{~kg}^{-1} \mathrm{~h}^{-1}$ at $6^{\circ} \mathrm{C}$ and $218 \mathrm{mg} \mathrm{O}_{2} \mathrm{~kg}^{-1} \mathrm{~h}^{-1}$ at $18^{\circ} \mathrm{C}$, i.e. higher than the $A M R$ values we measured in sole. Comparison of our results with those of Duthie (1982) reveals that AMR in flounder Platichthys flesus, common dab Limanda limanda and lemon sole Microstomus kitt also exceed $A M R$ values found in the common sole. For instance, $A M R$ of a $100 \mathrm{~g}$ dab attained 141, 181 and $226 \mathrm{mg} \mathrm{O}_{2} \mathrm{~kg}^{-1} \mathrm{~h}^{-1}$ at 5 , 10 and $15^{\circ} \mathrm{C}$ respectively, when $A M R$ in sole was estimated at 61, 97 and $138 \mathrm{mg} \mathrm{O}_{2} \mathrm{~kg}^{-1} \mathrm{~h}^{-1}$.

The $A M R$ of the European sea bass, which generally shares the same environment as sole, is approximately 4 times higher, i.e. $586 \mathrm{mg} \mathrm{O}_{2} \mathrm{~kg}^{-1} \mathrm{~h}^{-1}$ at $22.5^{\circ} \mathrm{C}$ (Claireaux \& Lagardère 1999). Bass and sole can also be distinguished on the basis of their level of thermal specialisation (Huey \& Stevenson 1979). For instance, we can compare the temperature range over which each species can sustain a metabolic rate corresponding to $80 \%$ of their maximal $M S$. In sole, this range is $10^{\circ} \mathrm{C}\left(13.3\right.$ to $\left.22.9^{\circ} \mathrm{C}\right)$, whereas in bass it is only $5^{\circ} \mathrm{C}\left(19.5\right.$ to $24.8^{\circ} \mathrm{C}$, Claireaux $\&$ Lagardère 1999). A parallel can be drawn between the relatively low susceptibility of sole metabolism to temperature changes and its poor locomotive ability. Physiology, morphology and behaviour are closely related (Huey 1991). It can be hypothesised that the reduced behavioural repertoire of sole connects with a greater subordination of thermoregulation to the physiological/biochemical mechanisms involved in the environmental adaptation. Greater mobility, on the contrary, is generally associated with broader behavioural abilities. This allows a faster and possibly more temperaturesensitive metabolism, providing such species with an efficient means for tuning their metabolism according to their physiological needs, e.g. feeding/starving (Sogard \& Olla 1996) or to the environmental conditions encountered, e.g. hypoxia (Schurmann \& Steffensen 1992). 
In the present study, we quantified the variations in aerobic $M S$ that sole are liable to experience when exposed to given changes in ambient temperature and oxygenation (Eq. 1). The $M S$ represents the energetic framework within which all physiological functions must be accommodated. Its maximisation reduces the occurrence of situations requiring energetic prioritisation between conflicting physiological processes and thereby has positive repercussions on fish biological performance (Priede 1985, Evans 1990). In this regard, the temperature where $M S$ is maximised also yields to maximised growth performance in sole (Anonymous 1983), in turbot (Mallekh \& Lagardère 2002) and bass (Lefrançois 2001). On the contrary, fish with reduced $M S$ are likely to experience impaired performance (Neill \& Bryan 1991). For instance, the temperature where $M S$ is nil $\left(27.2^{\circ} \mathrm{C}\right)$ corresponds to the incipient lethal temperature of sole (Anonymous 1983).

As noticed in other fish species (Randall 1968, Cech et al. 1976, Farrell et al. 1996, Farrell 1997), the maximal heart beat frequency of the sole increased linearly with temperature (Eq. 6). The calculated $Q_{10}$ of 2.3 is within the range of values classically reported in teleosts (1.3 to 3.0, Farrell 1997). Furthermore, our measures of $A H R$ agree with the observations reported on free-swimming sole by Sureau \& Lagardère (1991). The highest $H R$ they telemetered was 50 beats $\mathrm{min}^{-1}$ (temperature between 8 and $12^{\circ} \mathrm{C}$ ), while our model predicts $A H R$ between 31 and 47.5 beats $\mathrm{min}^{-1}$ in the same thermal range.

The linear increase of $A H R$ with temperature contrasts with the concomitant bell-shaped relationship observed with $A M R$. A parallel can be drawn between this observation and the hypothesis made by Farrell (1997) concerning the influence of temperature on cardiac output. It was reported that, in salmonids, cardiac output followed a bell-shaped relationship with temperature. Farrell (1997) hypothesised that the ascending portion of that relationship resulted from a temperature-driven increase in both $H R$ and stroke volume. Farrell (1997) also proposed that above a certain thermal threshold, the still increasing $H R$ gradually resulted in reduced cardiac filling and/or cardiac contractility, bringing about a progressive decrease in stroke volume and cardiac output. On the same basis, it can be hypothesised that in sole, the observed divergence in the course followed by $A M R$ and $A H R$ at temperatures above $20^{\circ} \mathrm{C}$ originates from a stroke volume-related decrease in cardiac output.

\section{Effect of oxygen}

Together with temperature, oxygen is an important determinant of MS. During progressive hypoxia,
$M \mathrm{O}_{2 \text { max }}$ gradually dropped down the $\mathrm{LOC}_{\mathrm{MO}_{2}}$ curve, bringing about a reduction of sole $M S$. On the other hand, hyperoxic conditions did not influence sole $M O_{2 \max }$. This corroborates similar observations made on European sea bass Dicentrarchus labrax (Lefrançois 2001) and turbot Scophthalmus maximus (Mallekh \& Lagardère 2002). In the latter species, neither food intake (Mallekh et al. 1998) nor growth (Person-Le Ruyet et al. 2001) was improved when fish were raised under hyperoxic conditions. In rainbow trout Oncorhynchus mykiss, the maximal oxygen consumption measured in forced-swum fish and the critical swimming speed $\left(U_{\text {crit }}\right)$ are not raised by hyperoxia either (Duthie \& Hughes 1987).

The present study also shows that in sole $H R_{\max }$ is not influenced by hyperoxic conditions (ca. 150 to $175 \%$ air saturation, Fig. 6). To our knowledge, only 1 study reports values of $H R_{\max }$ in hyperoxic conditions (Lefrançois 2001). In that study, we showed that neither in sole nor in sea bass is $H R_{\max }$ affected by oxygen supersaturation.

The concept of the $L O C_{H R}$ curve is based on the assumption that for any given $H R$ we considered a limiting oxygen concentration ( $L O C$ ), below which $H R$ switches from being oxygen-independent to being oxygen-dependent. Bradycardia is a common cardiovascular response in teleosts facing hypoxia (Satchell 1971, Randall 1982). Satchell (1971) pointed out that the ambient oxygen level that triggered bradycardia was species specific (see also Marvin \& Burton 1973, Cech et al. 1977, Fritsche \& Nilsson 1989). The present results (Figs. $8 \& 9$ ) suggest that the oxygen level at which bradycardia occurs, i.e. the limiting oxygen concentration $\left(L O C_{H R}\right)$, also depends on the cardiovascular work load at the heart at the onset of hypoxia. Lefrançois et al. (1998) observed that sea bass fed to satiation displayed $H R$ near the $L O C_{H R}$ curve defined for this species. In these conditions every subsequent mild (90\% sat) and short (less than $5 \mathrm{~min}$ ) hypoxic episode was associated with bradycardia. Reciprocally, in Scyliorhincus canicula presenting a low $H R$, bradycardia was observed only under severe hypoxia (Taylor 1985). In Torpedo marmorata (Hughes 1978) or Gobius cobiti (Berschick et al. 1987) which both exhibited low $H R$, bradycardia was never observed. Our results suggest that in fully active sole a reduction of ambient oxygen to $50 \%$ air saturation is sufficient to trigger bradycardia.

Based on the measures of $H R_{\max }, M O_{2 \max }, S M R$ and $M S$, the present study aimed at gaining an holistic view of the combined effect of temperature and oxygen on the metabolic and cardiovascular performances of a poorly studied flatfish species. The connections that we have tried to establish between physiology, morphology and behaviour are clearly ten- 
tative. However, the proposed approach highlights possible avenues of future research to disentangle, understand and predict the ecological repercussions of environmental forcing on fish performance at large.

Acknowledgements. This study was financially supported by IFREMER, the Institut Français pour la Recherche et l'Exploitation de la Mer. The authors are indebted to Marcel Guillaut and Michel Prineau for their technical help, and thank P. Domenici, S. Lefebvre and the referees for helpful comments on the manuscript. All experimental procedures in this work comply with the current laws in France.

\section{LITERATURE CITED}

Anonymous (1983) Fiches biotechniques d'aquaculture. La sole. CNEXO, Brest

Armstrong JD (1986) Heart rate as an indicator of activity, metabolic rate, food intake and digestion in pike, Esox lucius. J Fish Biol 29:207-221

Beamish FWH (1964) Respiration of fish with special emphasis on standard oxygen consumption, III. Influence of oxygen. Can J Zool 42:355-366

Berschick P, Bridges CR, Grieshaber MK (1987) The influence of hyperoxia, hypoxia and temperature on the respiratory physiology of the intertidal rockpool fish Gobius cobitis pallas. J Exp Biol 130:369-387

Bryan JD, Kelsch SW, Neill WH (1990) The maximum power principle in behavioral thermoregulation by fishes. Trans Am Fish Soc 119:611-621

Bushnell PG, Brill RW (1991) Responses of swimming skipjack (Katsuwonus pelamis) and yellowfin (Thunnus albacares) tunas to acute hypoxia, and a model of their cardiorespiratory function. Physiol Zool 64:787-811

Cech JJ, Bridges DW, Rowell DM, Balzer PJ (1976) Cardiovascular responses of winter flounder, Pseudopleuronectes americanus (Walbaum), to acute temperature increase. Can J Zool 54:1383-1388

Cech JJ, Rowell DM, Glasgow JS (1977) Cardiovascular responses of the winter flounder Pseudopleuronectes americanus to hypoxia. Comp Biochem Physiol 57A: 123-125

Cech JJ, Mitchell SJ, Castleberry DT, McEnroe M (1990) Distribution of california stream fishes: influence of environmental temperature and hypoxia. Environ Biol Fishes 29: 95-105

Chabot D, Dutil JD (1999) Reduced growth of Atlantic cod in non lethal hypoxic conditions. J Fish Biol 55:472-491

Claireaux G, Lagardère JP (1999) Influence of temperature, oxygen and salinity on the metabolism of European sea bass. J Sea Res 42:157-168

Claireaux G, Webber DM, Kerr SR, Boutilier RG (1995) Physiology and behaviour of free swimming atlantic cod (Gadus morhua) facing fluctuating salinity and oxygenation conditions. J Exp Biol 198:61-69

Claireaux G, Webber DM, Lagardère JP, Kerr SR (2000) Influence of water temperature and oxygenation on the aerobic metabolic scope of Atlantic cod (Gadus morhua). J Sea Res 44:257-265

Duthie GG (1982) The respiratory metabolism of temperature-adapted flatfish at rest and during swimming activity and the use of anaerobic metabolism at moderate swimming speeds. J Exp Biol 97:359-373
Duthie GG, Hughes GM (1987) The effects of reduced gill area and hyperoxia on the oxygen consumption and swimming speed of rainbow trout. J Exp Biol 127:349-354

Evans DO (1990) Metabolic thermal compensation by rainbow trout: effects on standard metabolic rate and potential usable power. Trans Am Fish Soc 119:585-600

Farrell AP (1997) Effects of temperature on cardiovascular performance. In: Wood CM, McDonald DG (eds) Global warming implications for freshwater and marine fish. Society of Experimental Biology, Seminar Series 61. Cambridge University Press, Cambridge, p 135-153

Farrell AP, Gamperl AK, Hicks JM, Shiels HA, Jain KE (1996) Maximum cardiac performance of rainbow trout (OnCorhynchus mykiss) at temperatures approaching their upper lethal limit. J Exp Biol 199:663-672

Fritsche R, Nilsson S (1989) Cardiovascular responses to hypoxia in the Atlantic cod, Gadus morhua. Exp Biol 48: $153-160$

Fry FE (1971) The effect of environmental factors on the physiology of fish. In: Hoar WS, Randall DJ (eds) Fish physiology, Vol VI. Academic Press, New York, p 1-98

Gehrke PC (1988) Response surface analysis of teleost cardiorespiratory responses to temperature and dissolved oxygen. Comp Biochem Physiol A 89:587-592

He P (1991) Swimming endurance of the Atlantic cod, Gadus morhua L., at low temperatures. Fish Res 12:65-73

Huey RB (1991) Physiological consequences of habitat selection. Am Nat 137:91-115

Huey RB, Stevenson RD (1979) Integrating thermal physiology and ecology of ectotherms: a discussion of approaches. Am Zool 19:357-366

Hughes GM (1978). On the respiration of Torpedo marmorata. J Exp Biol 73:85-107

Huntingford FA (1993) Can cost-benefit analysis explain fish distribution patterns. J Fish Biol 43:289-308

Lefrançois C (2001) Effet de l'environnement abiotique (température et oxygène) sur le métabolisme énergétique, la physiologie cardiaque et le comportment de deux espèces cotières: le bar, Dicentrarchus labrax, et la sole, Solea solea. PhD thesis, University of La Rochelle

Lefrançois C, Claireaux G, Lagardère JP (1998) Heart rate telemetry to study environmental influences on fish metabolic expenditure. In: Lagardère JP, Bégout-Anras ML, Claireaux G (eds) Developments in hydrobiologyadvances in invertebrates and fish telemetry. Kluwer Academic Publishers, Dordrecht, p 215-224

Lefrançois C, Odion M, Claireaux G (2001) An experimental and theoretical analysis of the effect of added weight on the energetics and hydrostatic function of the swimbladder of European sea bass (Dicentrarchus labrax). Mar Biol 139:13-17

Lewis AE, Muntz WRA (1984) The effect of external ultrasonic tagging on the swimming performance of rainbow trout, Salmo gairdneri Richardson. J Fish Biol 25:577-585

Lucas MC, Priede IG, Armstrong JD, Gindy ANZ, De Vera L (1991) Direct measurements of metabolism, activity and feeding behaviour of pike, Esox lucius L., in the wild, by the use of heart rate telemetry. J Fish Biol 3:325-345

Mallekh R, Lagardère JP (2002) Effect of temperature and dissolved oxygen concentration on the metabolic rate of the turbot and the relationship between metabolic scope and feeding demand. J Fish Biol 60:1105-1115

Mallekh R, Lagardère JP, Bégout Anras ML, Lafaye JY (1998) Variability in appetite of turbot, Scophthalmus maximus under intensive rearing conditions: the role of environmental factors. Aquaculture 165:123-138

Marvin DE, Burton DT (1973) Cardiac and respiratory re- 
sponses of rainbow trout, bluegills and brown bullhead catfish during rapid hypoxia and recovery under normoxic conditions. Comp Biochem Physiol 46A:515-524

Mellas EJ, Haynes JM (1985) Swimming performance and behavior of rainbow trout (Salmo gairdneri) and white perch (Morone americana): effects of attaching telemetry transmitters. Can J Fish Aquat Sci 42:488-493

Neill WH, Bryan JD (1991) Responses of fish to temperature and oxygen, and response integration through metabolic scope. In: Brune DE, Tomasso JR (eds) Aquaculture and water quality, advances in world aquaculture. World Aquaculture Society, Baton Rouge, LA, p 30-57

Neill WH, Miller JM, Van der Veer HW, Winemiller KO (1994) Ecophysiology of marine fish recruitment: a conceptual framework for understanding interannual variability. Neth J Sea Res 32:135-152

Person-Le Ruyet J, Pichavant K, Vacher C, Le Bayon N, Severe A, Boeuf G (2002) Effects of $\mathrm{O}_{2}$ supersaturation on metabolism and growth in juvenile turbot (Scophthalmus maximus L.). Aquaculture 205:373-383

Petersen JK, Pihl L (1995) Responses to hypoxia of plaice, Pleuronectes platessa, and dab, Limanda limanda, in the south-east Kattegat: distribution and growth. Environ Biol Fish 43:311-321

Priede IG (1985) Metabolic scope in fishes. In: Tytler P, Calow P (eds) Fish energetics - new perspectives. Croom Helm, London, p 33-64

Priede IG, Tytler P (1977) Heart rate measure of metabolic rate in teleost fishes, Salmo gairdneri, Salmo trutta and Gadus morhua. J Fish Biol 10:231-242

Priede IG, Young AH (1977) The ultra sonic telemetry of cardiac rhythms of wild brown trout (Salmo trutta L.) as an indicator of bio-energetics and behaviour. J Fish Biol 10:299-318

Randall DJ (1968) Functional morphology of the heart in fishes. Am Zool 8:179-189

Randall D (1982) The control of respiration and circulation in fish during exercise and hypoxia. J Exp Biol 100:275-288

Rudstam LG, Magnuson JJ (1985) predicting the vertical distribution of fish populations: analysis of Cisco, Coregonus artedii, and Yellow perch, Perca flavescens. Can J Fish Aquat Sci 42:1178-1188

Satchell GH (1971) Circulation in fishes. Cambridge Univer-

Editorial responsibility: Otto Kinne (Editor),

Oldendorf/Luhe, Germany sity Press, Cambridge

Schurmann H, Steffensen JF (1992) Lethal oxygen levels at different temperatures and the preferred temperature during hypoxia of the Atlantic cod, Gadus morhua. J Fish Biol 41:927-934

Schurmann H, Steffensen JF (1997) Effects of temperature, hypoxia and activity on the metabolism of juvenile Atlantic cod. J Fish Biol 50:1166-1180

Schurmann H, Claireaux G, Chartois H (1998) Changes in vertical distribution of sea bass (Dicentrarchus labrax L.) during a hypoxic episode. Hydrobiologia 371-372: 207-213

Sogard SM, Olla BL (1996) Food deprivation affects vertical distribution and activity of a marine fish in a thermal gradient: potential energy-conserving mechanisms. Mar Ecol Prog Ser 133:43-55

Sokal RR, Rohlf FJ (1981) Biometry. WH Freeman, New York

Steffensen JF, Bushnell PG, Schurmann H (1994) Oxygen consumption in four species of teleosts from Greenland: no evidence of metabolic cold adaptation. Polar Biol 14:49-54

Straskraba M, Gnauck A (1985) Freshwater ecosystems: modelling and simulation. Developments in environmental modelling, Vol 8. Elsevier, Amsterdam

Sureau D, Lagardère JP (1991) Coupling of heart rate and locomotor activity in sole, Solea solea (L.), and bass, Dicentrarchus labrax (L.), in their natural environment by using ultrasonic telemetry. J Fish Biol 38:399-405

Taylor EW (1985) Control and co-ordination of gill ventilation and perfusion. In: Laverack MS (ed) Physiological adaptations of marine animals. Symp Soc Exp Biol. Cambridge: The Company of Biologists, Cambridge, p 123-161

Thorarensen H, Gallaugher PE, Farrell AP (1996) The limitations of heart rate as a predictor of metabolic rate in fish. J Fish Biol 49:226-236

van den Thillart G, Dalla Via J, Vitali G, Cortesi P (1994) Influence of long-term hypoxia exposure on the energy metabolism of Solea solea. I. Critical $\mathrm{O}_{2}$ levels for aerobic and anaerobic metabolism. Mar Ecol Prog Ser 104: 109-117

Von Ende CN (1993) Design and analysis of ecological experiments. Repeated-measures analysis: growth and other time-dependent measures. Chapman \& Hall, New York

Submitted: January 29, 2001; Accepted: April 29, 2003

Proofs received from author(s): September 2, 2003 